\title{
School nutritional capacity, resources and practices are associated with availability of food/ beverage items in schools
}

\author{
Louise C Mâsse ${ }^{*}$ and Judith E de Niet
}

\begin{abstract}
Background: The school food environment is important to target as less healthful food and beverages are widely available at schools. This study examined whether the availability of specific food/beverage items was associated with a number of school environmental factors.

Methods: Principals from elementary $(n=369)$ and middle/high schools $(n=118)$ in British Columbia $(B C)$, Canada completed a survey measuring characteristics of the school environment. Our measurement framework integrated constructs from the Theories of Organizational Change and elements from Stillman's Tobacco Policy Framework adapted for obesity prevention. Our measurement framework included assessment of policy institutionalization of nutritional guidelines at the district and school levels, climate, nutritional capacity and resources (nutritional resources and participation in nutritional programs), nutritional practices, and school community support for enacting stricter nutritional guidelines. We used hierarchical mixed-effects logistic regression analyses to examine associations with the availability of fruit, vegetables, pizza/hamburgers/hot dogs, chocolate candy, sugar-sweetened beverages, and french fried potatoes.
\end{abstract}

Results: In elementary schools, fruit and vegetable availability was more likely among schools that have more nutritional resources ( $\mathrm{OR}=6.74$ and 5.23 , respectively). In addition, fruit availability in elementary schools was highest in schools that participated in the BC School Fruit and Vegetable Nutritional Program and the BC Milk program ( $\mathrm{OR}=4.54$ and $\mathrm{OR}=3.05$, respectively). In middle/high schools, having more nutritional resources was associated with vegetable availability only $(\mathrm{OR}=5.78)$. Finally, middle/high schools that have healthier nutritional practices (i.e., which align with upcoming provincial/state guidelines) were less likely to have the following food/ beverage items available at school: chocolate candy $(\mathrm{OR}=.80)$ and sugar-sweetened beverages $(\mathrm{OR}=.76)$.

Conclusions: School nutritional capacity, resources, and practices were associated with the availability of specific food/beverage items in BC public schools. Policies targeting the school environment are increasingly being considered as one of the strategies used to address childhood obesity, as a result it is important to further understand the factors associated with the availability of specific food/beverage items at school.

Keywords: Nutrition, School environment, Organizational support, School policy, Availability of food, Availability of sweetened beverages, Fruit, Vegetables, Junk food, Less healthful food

\footnotetext{
* Correspondence: Imasse@cfri.ubc.ca

University of British Columbia, School of Population and Public Health,

F508-4480 Oak Street, Vancouver, BC V6H 3V4, Canada
} 


\section{Background}

Overwhelming evidence demonstrates a worldwide increase in childhood obesity [1] and Canada is no exception to this trend [1]. In 2004, one quarter (26\%) of Canadian children aged 2 to 17 years were either overweight or obese, representing a sharp increase from a combined prevalence of $15 \%$ in 1978/1979 [1]. While obesity is a complex and multi-factorial problem, many have suggested focusing on the school food environment as part of a comprehensive multi-setting approach to address childhood obesity [2].

The availability of less healthful food and beverages in schools is widespread [3-5]. Despite recent changes to improve the school food environment, the availability of some high fat food such as pizza and hamburgers, remains alarmingly high in U.S. schools $(73.9 \%$ and $82.6 \%$, respectively for elementary and middle/ high schools) [5]. Similar to U.S. schools, Canadian elementary schools have fewer vending machines; however, less healthful food and beverages are widely available to all grades as they are made available through other outlets (e.g., cafeteria, school stores) [3].

The school food environment has been shown to influence student eating behaviors [6-12]. In schools where less healthful food and beverages are widely available, students have higher intake of these items, consume fewer fruit and vegetables, and have higher total fat intake [7-11]. In addition, increasing the availability of healthful food and beverages in schools has been associated with improved dietary intake [13,14]. Although evidence linking the school food environment with student Body Mass Index (BMI) is mixed [6], both the frequency at which fruit and vegetables are available and the availability of less healthful food in vending machines or other venues at school have been associated with higher BMI in students [14]. As the school food environment may influence the eating behaviors of children in that context, it is important to understand the factors associated with the availability of specific food/ beverage items at schools.

The school food environment may be influenced by several factors, such as policies/guidelines that limit the availability of certain food/beverages items, restricting the use of food as rewards in the classroom, setting standards for nutrition education, restricting certain marketing practices, having adequate resources and capacity at the school and district levels, having a supportive school community, having access to nutritional expertise locally, having access to nutritional programs that promote healthy eating, and having a favorable socio-demographic profile [15-22]. With the exception of school food policies/guidelines, where emerging data links policies with students' dietary intake and BMI [18,23-27], the extent to which other school factors are related to the availability of specific food/beverage items at school has received little attention. However, uptake of nutrition and health programs in the school setting have been found to be highest in schools that have more supportive policies; better organizational climate, capacities and resources; and have more support from school principals [28-30]. This suggests that these environmental factors might be associated with the availability of specific food/beverage items in the school setting. Therefore, the purpose of this study was to determine whether the availability of fruit, vegetables, pizza/hamburgers/hot dogs, chocolate candy, sugar-sweetened beverages, and french fried potatoes was associated with a number of school environmental factors: (1) policy institutionalization of nutritional guidelines at the district and school levels, (2) climate, (3) nutritional capacity and resources, (4) nutritional practices at school, and (5) school community support for enacting stricter nutritional guidelines at school. These associations were examined separately for elementary schools and middle/high schools. Differences were expected given that food and beverages are more likely available in higher grades [5,31].

Note we examined these associations in schools located in British Columbia (BC), Canada which has a markedly different school food environment than other countries. Unlike other countries, Canada does not have a federally subsidized school meal program [32]. Some school districts, through funding from the Ministry of Education, enable schools to offer school meal programs to vulnerable students (breakfast program, hot lunch program, bag lunch program, or snack program). School meal programs are often managed through partnerships and donations schools/ districts have negotiated with external agencies. As many schools do not have on-site cooking facilities, schools can contract food vendors to prepare the school meals following the non-mandated guidelines published by the province/ state for administering the program. In addition, in our context the availability of permanent food outlets is much lower in elementary schools than in middle/high schools (45\% versus $95 \%$ have permanent food outlets, respectively); however, $82 \%$ of elementary schools have external vendors contracted to bring in A La Carte lunch options (e.g., pizza, hamburgers, hot dogs), varying from multiple times a week to a few times per month [3]. Importantly, food and beverages made available or sold to students were not mandated to meet any nutritional guidelines until the 2008/2009 school year, as the province/state enacted guidelines to support healthy eating at schools which aligned with the 2007 Canada Food Guide [33].

\section{Methods}

\section{Participants}

Public school principals in BC were targeted for this study. Given the relatively small number of Francophone, Independent, First Nations, and alternative schools in 
$\mathrm{BC}$, principals of these schools were excluded as this study could not address their specific issues of these schools. Study approval was received in 43 of the 59 school districts (73\% response rate); however, three districts were excluded as they were participating in another study conducted by the same research team. Of the 1067 eligible principals, 513 principals completed the school environment survey (48\% response rate). Respondents from schools that included all grades (i.e., elementary, middle, and high schools $n=13$ ) or had less than 50 students $(n=13)$ were excluded. In total, 369 elementary schools and 118 middle/high schools from 38 districts provided data for the analyses.

\section{Procedures}

This study was approved by the University of British Columbia Research Ethics Board. Prior to data collection, school district approval was obtained. In January of 2008, principals received a package that included an invitational letter, consent form, a hard copy of the school environment survey (which took 30 minutes to complete), and a pre-paid self return envelope. Approximately two weeks after the invitational package was mailed, a research staff member contacted the principals to determine if they had specific questions about the study. Principals who did not return the school environment survey received a second mailing. If completed surveys were not received within a 3-week period, principals received a reminder email with a link to the online survey as an alternative way of completing the survey. Principals were encouraged to seek out the expertise of their staff if assistance was needed for filling out sections of the survey (e.g., the nutrition environment section). Data collection ended in June 2008. Principals received a $\$ 10$ gift card for completing the survey.

\section{Measures}

Operationalization of the measures integrates central constructs from the Theories of Organizational Change and elements of Stillman's Tobacco Policy Framework adapted for the context of this study (see Figure 1). From the Theories of Organizational Change, our assessment framework incorporates assessment of policy institutionalization (e.g., school and district policies, guidelines, or requirements) as well as measures of organizational climate, capacity and resources, and practices to support healthy eating and nutrition education at schools. From Stillman's Tobacco Policy Framework [34], our measurement framework includes assessment of internal and external influences that may impede or facilitate implementation of healthy eating practices or policies at school. Whenever possible, existing measures were used to assess the constructs of interests. Content review of our measures was conducted

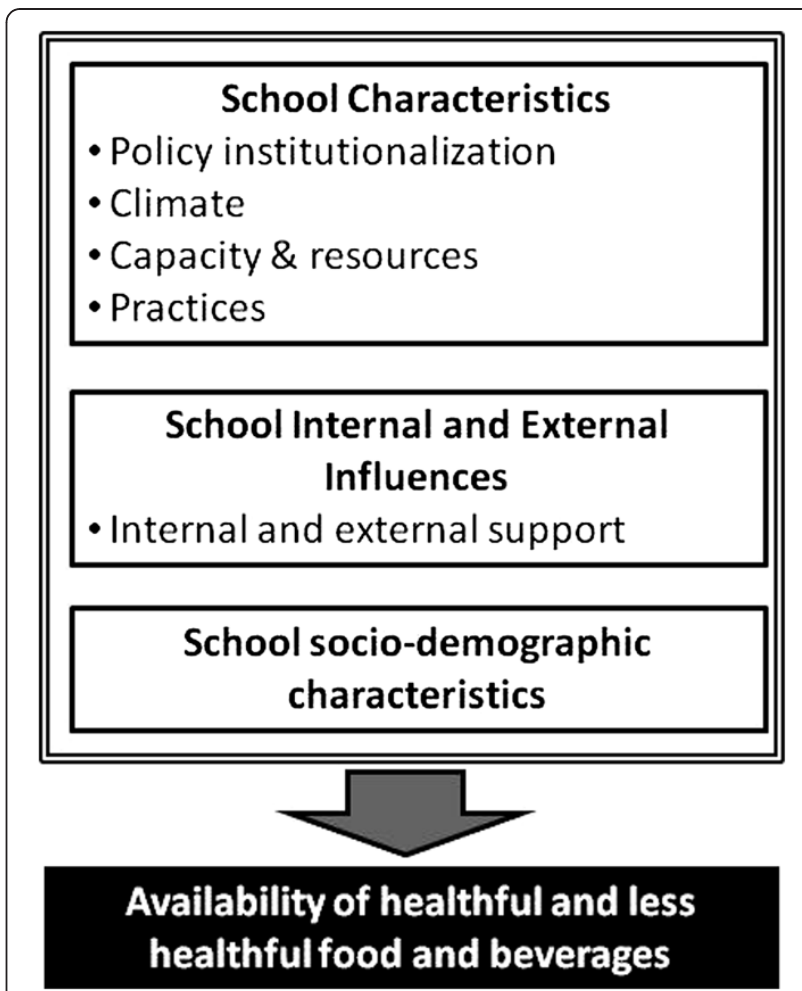

Figure 1 School environmental factors hypothesized to be associated with availability of specific food/beverage items.

by having relevant provincial Ministry staff and school principals review the relevance of the items in the context of BC. A description of the measures follows as well as a description of the psychometric properties of the scales used to measure these constructs.

\section{School characteristics (independent variables)}

Policy institutionalization measured the extent to which districts and schools had nutritional policies/guidelines/ requirements related to the availability of food and beverages, qualifications of food personnel, and nutrition education at school. Two scales assessed policy institutionalization: [1] District guidelines is a 3-item scale that assessed whether principals perceived their district's guidelines to be average, above average, or below average compared to other districts with respect to food and beverages sold or made available to students, staffing requirements for school food personnel, and nutrition education requirements; and [2] School guidelines is a 7 -item scale that measured whether schools have guidelines in place that ban food advertizing, prohibit use of less healthful food as reward, require healthier food choices be subsidized, provide educational requirements for the school food 
personnel, and include requirements for nutrition education. Response options for these items included "no", "in the process of developing guidelines", and "yes". These options were dichotomized for analysis purposes ("0" for "no" and "in the process" and " 1 " for "yes"). In addition, the scale included two items that measured whether the school incorporates the Canada's Food Guide into the curriculum with "yes" and "no" as response options.

Climate assessment was derived from Hoy's school climate measure [35-38]. The scale, using seven response options, includes 10 semantic differential items that measured whether the overall school climate is collegial, supportive, conciliatory, friendly, warm, open, welcoming, accepting of change, accommodating, and trusting.

Capacity and resources measured two dimensions: nutritional resources and program participation. Nutritional resources is a 5-item scale based on Hoy's organizational Health Inventory of elementary schools [39]. The scale assessed whether principals perceived their school's nutritional resources to be average, above average, or below average compared to other schools with respect to the number of staff involved in food preparation and management, eating facility, access to a local nutritionist, access to caterers and vendors that offer healthier food options, and opportunities to make healthy food choices at school. Program participation was measured with two items: one assessing participation in the BC Milk Program and the other assessing participation in the BC School Fruit and Vegetable Nutritional Program (BCSFVNP), with "yes" and "no" as response options. The BC Milk program subsidizes the costs of milk to students in K-12 and in elementary schools the milk can be delivered in the classroom instead of the cafeteria. The BCSFVNP was launched in 2005 and provides K-12 schools with 14 free deliveries of at least two servings of locally grown fresh fruit and/or vegetables for every student throughout the school year. Both programs are run by school volunteers.

School nutrition practices is a 3-item index that assessed whether current school practices are aligned with next school years' upcoming mandated provincial/ state guidelines that eliminate the availability of less healthful food and beverages in schools and follows the 2007 Canada's Food Guide eating recommendations [33]. Specifically, this index assessed whether schools implemented the guidelines for food and beverages sold or made available to students in the following locations: snack bar/school store(s); vending machine(s); and cafeteria. Response options for these items included "no", "in the process of developing requirements", and "yes". These options were dichotomized for analysis purposes ("0" for "no" and "in the process" and " 1 ' for "yes") and averaged across the three items.

\section{School internal and external influences (independent variables)}

Internal and external support is a 7-item scale that assessed perceived support from parents, staff, students, and the larger community for eliminating less healthful food and beverages in schools as well as assessing whether principals believed schools can play a role in addressing childhood obesity. All items were measured on a 4-point Likert-scale (strongly disagree to strongly agree).

\section{School socio-demographic characteristics (covariates)}

School size (total number of students) and school setting (categorized as inner city/urban, suburban, or rural) were included in the analyses as covariates.

\section{Availability of specific food/beverage items (dependent variables)}

The School Health Policies and Programs Study (SHPPS) questions were used to assess availability of specific food/ beverage items at school for lunch in a typical week [40]. The availability of the following food/beverage items were measured: [1] fruit; [2] vegetables; [3] pizza/hamburgers/ hot dogs; [4] chocolate candy; [5] sugar-sweetened beverages (e.g., pop, iced tea, sport drinks or fruit drinks that are not $100 \%$ fruit juice); and [6] french fried potatoes.

\section{Psychometric properties of the measures}

The psychometric properties of the scales were assessed in the larger sample using exploratory factor analysis. We extracted a 5-factor solution using the principal component extraction method with a promax rotation. Results from the factor analysis showed that a 5-factor solution replicated the hypothesized factor structure with the exception of two items: one item (the internal and external support item that measured whether principals believed schools can play a role in addressing childhood obesity) cross-loaded on two factors (internal and external support and policy institutionalization school guidelines); and another item had a low factor loading (.24) (the policy institutionalization - school guidelines item that measured requirements for nutrition education in schools). The 5 -factor solution explained $58 \%$ of the total variance and each scale had adequate internal consistency (Cronbach alpha $(\alpha)$ ), although one was slightly less than the acceptable cut-off of .70 (Policy institutionalization - district guidelines $\alpha=.79$ with factor loadings ranging from .78 to .89 ; Policy institutionalization - school guidelines $\alpha=.64$ with factor loadings ranging from .50 to .68 (except one item had a loading of .24); Climate $\alpha=.94$ with factor loadings ranging from .63 to .88; Capacity \& resources nutritional resources $\alpha=.72$ with factor loadings ranging from .62 to .73; and Internal and external support 
$\alpha=.72$ with factor loadings ranging from .30 to .73). Correlations among factors were low (less than .30).

\section{Statistical analyses}

All analyses were conducted using the STATA software version 11.1 (StataCorp, Texas USA). Nine hierarchical mixed-effects logistic regressions (xtmelogit) were employed to address the research questions. To account for the nested structure of the data, the district code was entered in the analyses. Multivariate associations were examined by including the covariates and all the independent variables in the model. Separate analyses were conducted for elementary schools and middle/high schools. Analyses for the elementary schools were restricted to food and beverages with more than $10 \%$ availability. To account for multiple comparisons, significance level was set at a stringent alpha level of .01 and trends toward significance were set at an alpha level of 05 .

Missing data were imputed using multiple imputation techniques (missing data ranging from 0.6 to $15.8 \%$ ). All missing data were imputed on the raw data using STATA's Expectation Maximization method which assumes the data is missing at random and unrelated to the outcome [41]. The dependent variables were included in the imputation model but only missing data on the covariates and independent variables were imputed. A total of five imputations were used.

\section{Results}

\section{School environmental factors}

Participating middle/high schools were significantly larger than the elementary schools (Table 1). Schools located in

Table 1 Descriptive information about the elementary $(N=366)$ and middle/high $(N=116)$ schools that participated in the study

\begin{tabular}{|c|c|c|c|c|}
\hline & & $\begin{array}{c}\text { Elementary } \\
\text { schools } \\
\% \text { or mean (SD) } \\
\text { [range] }\end{array}$ & $\begin{array}{c}\text { Middle/high } \\
\text { schools } \\
\text { \% or mean (SD) } \\
\text { [range] }\end{array}$ & $\begin{array}{c}\text { Group } \\
\text { comparisons } \\
x^{2} \text { or t-test } \\
p \text {-value }\end{array}$ \\
\hline \multirow{2}{*}{\multicolumn{2}{|c|}{ Number of schools per district }} & 9.7 & 3.1 & \\
\hline & & {$[1-38]$} & {$[1-11]$} & \\
\hline \multicolumn{5}{|c|}{ School socio-demographic characteristics } \\
\hline School size & & $283(146)$ & $838(424)$ & $t(1)=21.44$ \\
\hline$\left(\mathrm{N}_{\text {elementary schools }}\left(\mathrm{N}_{\mathrm{e}}\right)=379 ; \mathrm{N}_{\text {middle/high schools }}\left(\mathrm{N}_{\mathrm{mh}}\right)=117\right)$ & & {$[50-1062]$} & {$[121-2100]$} & $p<0.001^{* *}$ \\
\hline \multirow[t]{3}{*}{ School setting $\left(\mathrm{N}_{\mathrm{e}}=361 ; \mathrm{N}_{\mathrm{mh}}=116\right)$} & Urban & $36.8 \%$ & $31.9 \%$ & $x^{2}(1)=0.98$ \\
\hline & Suburban & $35.2 \%$ & $37.1 \%$ & $p=0.614$ \\
\hline & Rural & $28.0 \%$ & $31.0 \%$ & \\
\hline \multicolumn{5}{|c|}{ School characteristics } \\
\hline Policy institutionalization - District guidelines & & $2.1(0.4)$ & $2.1(0.4)$ & $t(1)=1.01$ \\
\hline$\left(N_{e}=314 ; N_{m h}=102\right)$ & & {$[1.0-3.0]$} & {$[1.0-3.0]$} & $p=0.312$ \\
\hline Policy institutionalization - School guidelines & & $0.4(0.3)$ & $0.4(0.2)$ & $t(1)=0.29$ \\
\hline$\left(\mathrm{N}_{\mathrm{e}}=254 ; \mathrm{N}_{\mathrm{mh}}=89\right)$ & & {$[0.0-1.0]$} & {$[0.0-1.0]$} & $p=0.773$ \\
\hline Climate & & $2.4(0.5)$ & $2.2(0.6)$ & $t(1)=-3.00$ \\
\hline$\left(\mathrm{N}_{\mathrm{e}}=352 ; \mathrm{N}_{\mathrm{mh}}=113\right)$ & & {$[1.0-3.0]$} & {$[1.0-3.0]$} & $p=0.003^{* *}$ \\
\hline Capacity \& resources - Nutritional resources & & $1.8(0.4)$ & $2.0(0.5)$ & $t(1)=4.64$ \\
\hline$\left(N_{e}=306 ; N_{m h}=104\right)$ & & {$[1.0-2.8]$} & {$[1.0-3.0]$} & $p<0.001^{* *}$ \\
\hline \multirow[t]{2}{*}{ Capacity \& resources - Program participation $\left(N_{e}=335 ; N_{m h}=93\right)$} & BCSFVNP (\% yes) & $43.3 \%$ & $25.8 \%$ & $\begin{array}{l}x^{2}(1)=9.31 \\
p=0.002^{* *}\end{array}$ \\
\hline & BC Milk Program (\% yes) & $38.2 \%$ & $25.8 \%$ & $\begin{array}{c}x^{2}(1)=4.89 \\
p=0.027^{*}\end{array}$ \\
\hline School nutrition practices & & $7.4(2.1)$ & $5.6(4.1)$ & $t(1)=-6.26$ \\
\hline$\left(\mathrm{N}_{\mathrm{e}}=359 ; \mathrm{N}_{\mathrm{mh}}=117\right)$ & & {$[0-10]$} & {$[0-10]$} & $p<0.001^{* *}$ \\
\hline \multicolumn{5}{|c|}{ School internal and external influences } \\
\hline Internal and external support & & $2.8(0.3)$ & $2.7(0.4)$ & $t(1)=-2.59$ \\
\hline$\left(N_{e}=273 ; N_{m h}=104\right)$ & & {$[1.9-3.9]$} & {$[1.7-3.9]$} & $p=0.010^{*}$ \\
\hline
\end{tabular}

$\mathrm{BCFVNP}=$ British Columbia Fruit and Vegetable Nutritional Program; $\mathrm{BC}=$ British Columbia.

** Significant at $\mathrm{p}<.01$.

* Trend towards statistical significance at $p<.05$. 
urban, suburban, and rural areas were well represented. Four of the six school characteristics differed significantly $(\mathrm{p}<.01)$ between elementary and middle/high schools (Table 1). Specifically, elementary schools had a better climate, less nutritional resources, higher participation in nutritional programs (BC Milk Program and the BCSFVNP), and better nutritional practices which align with upcoming provincial/state nutritional guidelines. In addition, elementary schools had significantly more support (internal and external) for enacting stricter nutritional guidelines at school than did middle/high schools.

\section{Availability of food and beverages}

The availability of fruit, vegetables, and pizza/hamburgers/ hot dogs was significantly lower in elementary schools compared to middle/high schools (Table 2). Chocolate candy, french-fried potatoes, and sugar-sweetened beverages were either not available or rarely available in elementary schools than compared to middle/high schools.

\section{School environmental factors associated with availability of specific food/beverage items}

Tables 3 and 4 summarize the results of the hierarchical mixed-effect logistic regression analyses examining which school environmental factors were associated with the availability of specific food/beverage items in elementary and middle/high schools.

\section{Associations with demographic characteristics}

Overall, the school demographic variables were not significantly associated $(\mathrm{p}<.01)$ with availability of specific food/beverage items in schools. However, the school setting showed a trend towards statistical significance $(\mathrm{p}<.05)$ with fruit availability in elementary schools and with pizza/hamburger/hot dog availability in middle/ high schools. Elementary schools located in suburban areas were less likely than those located in urban areas to report fruit availability (Odds Ratio $(\mathrm{OR})=0.39$, $\mathrm{p}=.015)$. In addition, middle/high schools located in rural areas were less likely than those located in urban areas to report pizza/hamburger/hot dog availability $(\mathrm{OR}=0.24, \mathrm{p}=.032)$.

\section{Associations with school characteristics}

In elementary schools, fruit and vegetable availability was more likely among schools that have more nutritional resources $(\mathrm{OR}=6.74$ and 5.23 , respectively), participate in the BCSFVNP $(\mathrm{OR}=4.54$ and 2.71 , respectively although only a trend towards statistical significance was observed for vegetable availability $(\mathrm{p}=.029))$, and participate in the BC Milk Program (OR = 3.05 for fruit availability; however, no significant association was observed for vegetable availability). Associations with fruit and vegetable availability differed markedly among middle/high schools. Having more nutritional resources was the only school characteristic associated with vegetable availability in middle/high schools $(\mathrm{OR}=5.78)$. In contrast, no school characteristics were significantly associated with fruit availability in middle/high schools. In addition, none of the school characteristics were associated with availability of pizza/ hamburgers/hot dogs in elementary and middle/high schools. Finally, middle/high schools that have healthier nutritional practices (i.e., which align with upcoming provincial/state guidelines) were less likely to have the following food/beverage items available at school chocolate candy $(\mathrm{OR}=.80)$, sugar-sweetened beverages $(\mathrm{OR}=.77)$, and french fried potatoes $(\mathrm{OR}=.80$, although only a trend towards statistical significance was observed $\mathrm{p}=.019)$.

\section{Associations with school internal and external influences}

School internal and external influences were not associated with availability of any food/beverage items examined in this study.

\section{Discussion}

Understanding environmental factors associated with the availability of specific food/beverage items at school is an important first step to ensure students have the opportunity to make healthy nutritional decisions at

Table 2 Percent of elementary $(\mathrm{N}=369)$ and middle/high schools $(\mathrm{N}=118)$ reporting availability of specific food/ beverage items

\begin{tabular}{lccc}
\hline Availability of & $\begin{array}{c}\text { Elementary } \\
\text { schools }\end{array}$ & $\begin{array}{c}\text { Middle/high } \\
\text { schools }\end{array}$ & $\begin{array}{c}\text { Group comparisons } x^{2} \\
p \text {-value }\end{array}$ \\
\hline Fruit & $27.9 \%$ & $74.6 \%$ & $x^{2}(1)=81.67 p<0.001^{* *}$ \\
Vegetables & $9.2 \%$ & $69.5 \%$ & $x^{2}(1)=179.03 p<0.001^{* *}$ \\
Pizza, hamburgers, or hot dogs & $13.8 \%$ & $63.6 \%$ & $x^{2}(1)=115.33 p<0.001^{* *}$ \\
Sugar-sweetened beverages (pop, iced tea, sport drinks or fruit drinks that are not & $5.4 \%$ & $62.7 \%$ & $x^{2}(1)=188.41 p<0.001^{* *}$ \\
$100 \%$ fruit juice) & & $41.5 \%$ & $x^{2}(1)=170.37 p<0.001^{* *}$ \\
French fried potatoes & $0 \%$ & $37.3 \%$ & $x^{2}(1)=151.26 p<0.001^{* *}$ \\
Chocolate candy & $0 \%$ & &
\end{tabular}

* Significant at $p<.01$

* Trend towards statistical significance at $p<.05$. 
Table 3 Factors associated with availability of fruit, vegetables and pizza/hamburgers/hot dogs in elementary ( $\mathrm{N}=369$ ) and middle/high schools $(\mathrm{N}=118)$

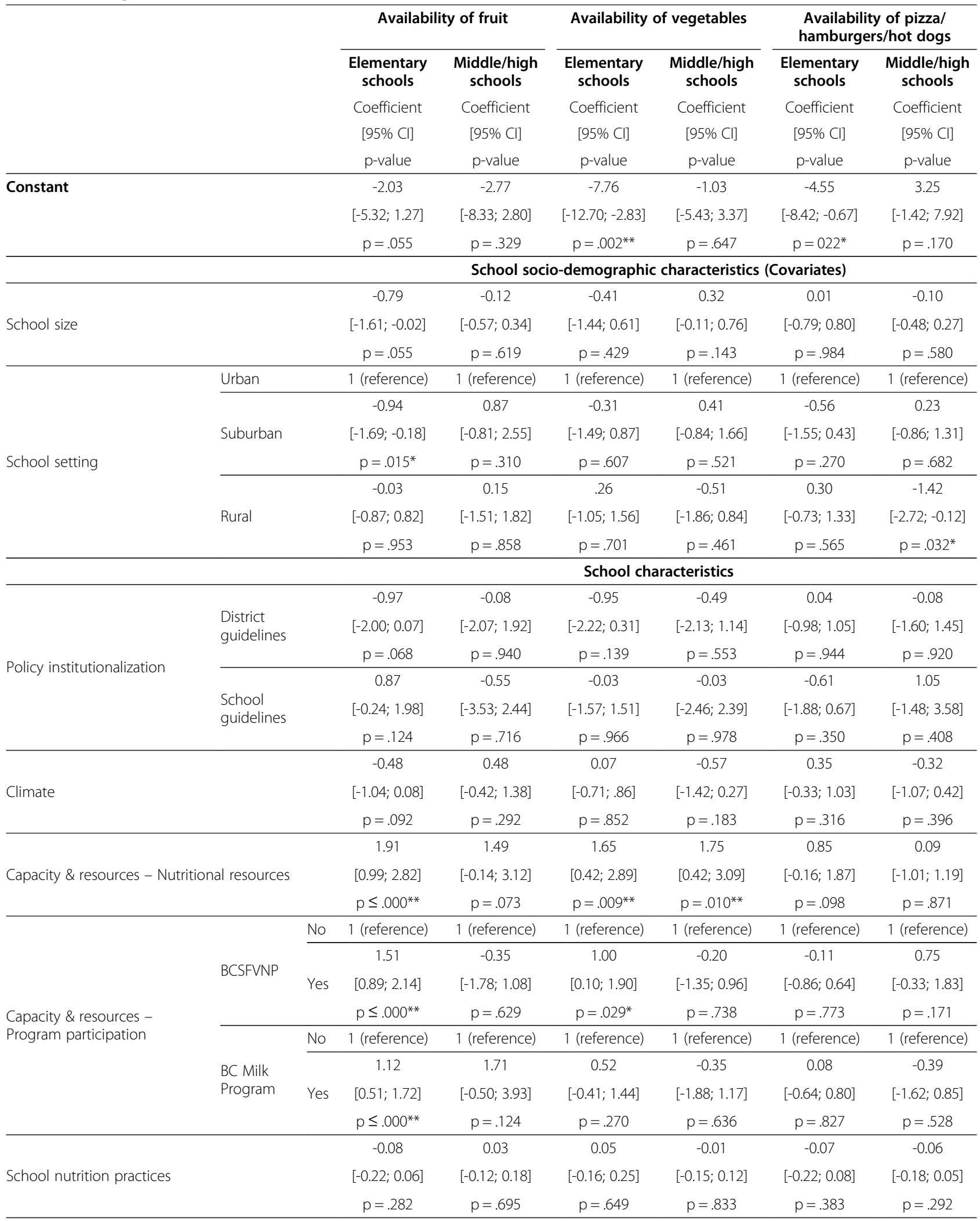


Table 3 Factors associated with availability of fruit, vegetables and pizza/hamburgers/hot dogs in elementary $(\mathrm{N}=369)$ and middle/high schools ( $\mathbf{N}=118$ ) (Continued)

\begin{tabular}{lccccccc}
\hline & \multicolumn{7}{c}{ School internal and external influences } \\
\hline & 0.21 & 0.03 & 1.02 & 0.08 & 0.26 & -0.54 \\
Internal and external Support & {$[-0.85 ; 1.26]$} & {$[-1.42 ; 1.48]$} & {$[-0.43 ; 2.47$} & {$[-1.16 ; 1.33]$} & {$[-0.84 ; 1.36]$} & {$[-1.66 ; 0.57]$} \\
& $p=.700$ & $p=.969$ & $p=.169$ & $p=.896$ & $p=.643$ & $p=.339$ \\
\hline
\end{tabular}

$\mathrm{Cl}=$ Confidence Interval; $\mathrm{BCSFVNP}=\mathrm{BC}$ School Fruit and Vegetable Nutritional Program; $\mathrm{BC}=$ British Columbia;

** Significant at $\mathrm{p}<.01$.

* Trend towards statistical significance at $p<.05$

school. As previously found, the availability of food and beverages was much lower in elementary schools than in middle/high schools [3-5]. Overall, three school environmental factors were associated with the availability of specific food/beverage items at schools: (1) having more nutritional resources, (2) participation in provincial/state nutritional programs, and (3) having nutritional practices that align with upcoming mandated provincial/state nutritional guidelines. Associations among these environmental factors with availability of specific food/beverage items were complex as they varied by the type of food/beverage items examined and differed by grade.

We found that fruit and vegetable availability was significantly higher in elementary schools that have more nutritional resources. To better understand these findings, it is important to highlight the nutritional context of Canadian schools in BC. Unlike other countries, Canada does not have a federally mandated school meal/ breakfast program [32]. As a result, many elementary schools in BC lack the amenities to refrigerate and store fresh fruit and vegetables and to prepare (cook or reheat) school meals. This partly explains why the availability of fruit and vegetables in BC elementary schools were found to be much lower than U.S. elementary schools (27\% versus $68 \%$, respectively [4]). In the context of $\mathrm{BC}$, our findings might highlight the need to equip elementary schools with an appropriate refrigeration system to enable them to provide more fruit and vegetables to their students. Furthermore, fruit and vegetable availability may be limited to being available as snacks only as many of the permanent food outlets (i.e., school stores, cafeteria, or vending machines) in elementary schools are not preparing meals. However, many elementary schools $(82 \%)$ have external vendors bringing $\mathrm{A}$ La Carte school lunch options (e.g., pizza, hamburgers, and hot dogs) at varied frequencies (e.g., multiple times a week to once a month) [3]. Potentially, fruit and vegetable availability might be increased by having external vendors change their offerings which could be achieved through policy strategies or incentive programs. In addition, nutritional resources were found to influence availability of food in middle/high schools; however, only an association with vegetable availability was observed. While food and beverages are more widely available in middle/high schools [3], there are still a large number of schools that do not offer lunch options. This might explain why we observed an association between vegetable availability and school nutrition resources in middle/ high schools. Unlike elementary schools, middle/high schools reported greater availability of fruit at schools which may explain why we did not find an association between fruit availability and nutritional resources in these schools.

We found that participation in the BCSFVNP was associated with fruit availability in elementary schools. These findings may suggest that fruit availability in elementary schools is a result of participating in the BCSFVNP. If this were the case, it would not reflect the broader availability of fruit on a daily basis since the BCSFVNP does not provide enough servings of fruit and vegetables to meet the required daily for each student. While the intent of the program is to encourage students to eat fresh fruit and vegetables, participation in such programs while important, is not enough to ensure that students eat fresh fruit and vegetables every day while at school. Alternatively, fruit availability in elementary schools might be higher in schools that participate in BCSFVNP as they have greater capability to store fresh fruit snacks. As the nutritional context of elementary schools in $\mathrm{BC}$ may be better equipped to provide fruit and vegetables as snacks rather than integrating them into the lunch meal (as lunch meals are often brought by external vendors), it might explain why we did not find an association with vegetables as fresh fruit snacks might be easier to sell since they require little or no preparation. Lack of significant associations in middle/high schools may have resulted since participation in the BCSFVNP is much lower in these schools. Although the program is equally available to all grades, more elementary schools than middle/high schools participate in this program (43\% versus $26 \%$, respectively). Participation in the program is free; however, it requires schools to identify a volunteer to administer and manage the distribution of these food every other week. Therefore, participation might be easier to manage in elementary schools, as these schools are typically smaller and have less complex schedules. Finally, the difference in associations between elementary and middle/high schools may be reflective of the fact that the availability of all food and 
Table 4 Factors associated with availability of chocolate candy, sugar-sweetened beverages, and french fried potatoes in middle/high $(\mathrm{N}=118)$ schools

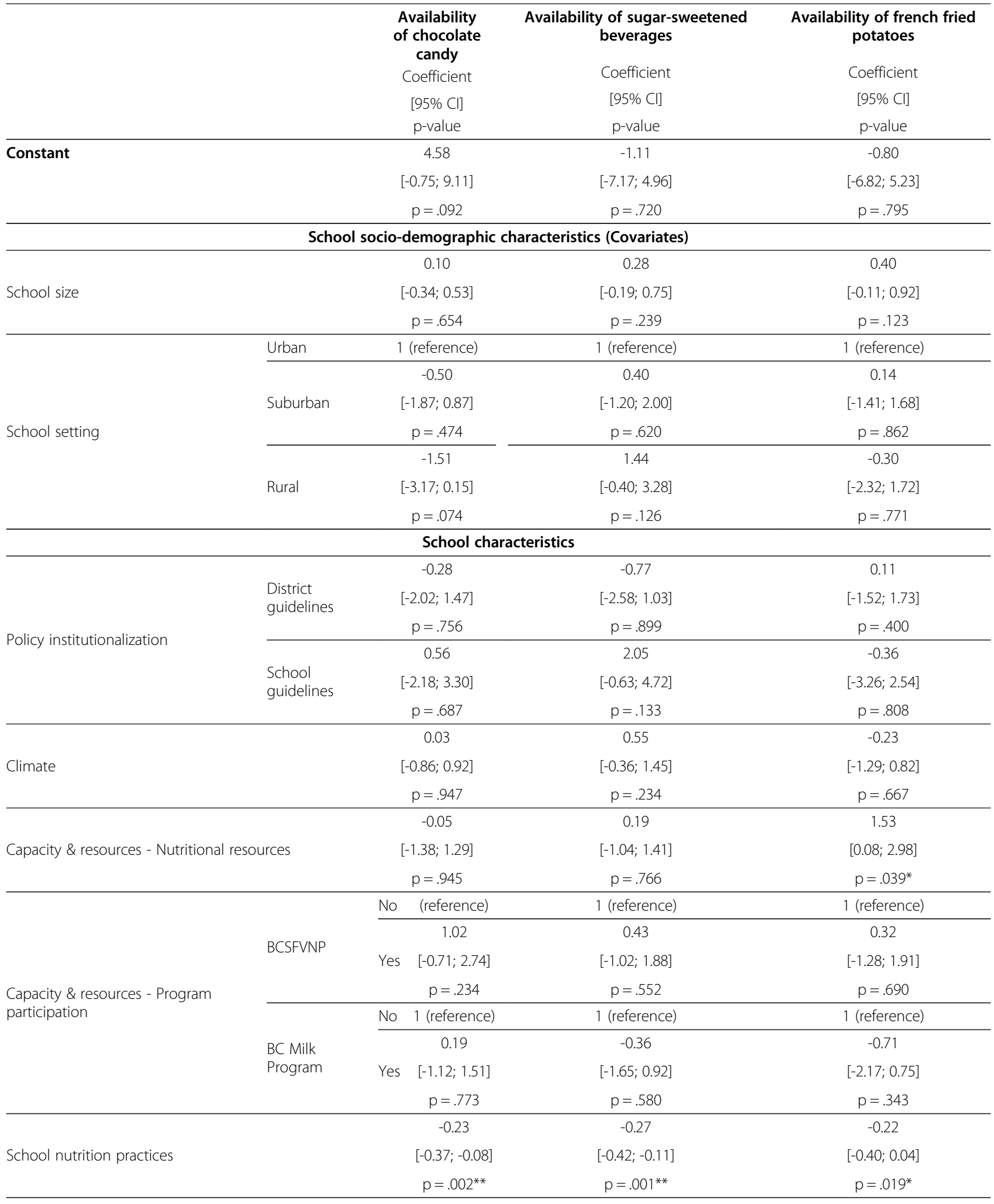


Table 4 Factors associated with availability of chocolate candy, sugar-sweetened beverages, and french fried potatoes in middle/high $(\mathbf{N}=\mathbf{1 1 8})$ schools (Continued)

\begin{tabular}{|c|c|c|c|}
\hline \multicolumn{4}{|c|}{ School internal and external influences } \\
\hline \multirow{3}{*}{ Internal and external Support } & -1.38 & -0.28 & -0.11 \\
\hline & {$[-2.84 ;-0.07]$} & {$[-1.75 ; 1.19]$} & {$[-1.80 ; 1.58]$} \\
\hline & $p=.063$ & $p=.706$ & $\mathrm{p}=.901$ \\
\hline
\end{tabular}

$\mathrm{Cl}=$ Confidence Interval; $\mathrm{BC}=$ British Columbia; $\mathrm{BCSFVNP}=\mathrm{BC}$ School Fruit and Vegetable Nutritional Program.

** Significant at $\mathrm{p}<.01$.

* Trend towards statistical significance at $p<.05$.

beverages in middle/high schools is markedly higher than in elementary schools [3]. Furthermore, we found that elementary schools participating in the BC Milk Program had more fruit availability. This finding can be explained by the nutrition environment of elementary schools in $\mathrm{BC}$. Participation in the BC Milk Program requires schools to have an appropriate refrigeration system. Once they are equipped with such a system, they are in a better position to store food items. Again, finding an association with fruit might reflect that it is easier to sell fruit as snacks compared to vegetables. Freshly prepared vegetables require more preparation and appropriate storage while many whole fruit do not. Fresh fruit snacks may also be more appealing than vegetable snacks and are, therefore, more likely to be purchased. This association was only observed in elementary schools and may be explained by the fact that middle/high schools participate less in the program (38\% versus $26 \%$, respectively).

Finally, we found that middle/high schools that have healthier nutritional practices aligning with upcoming mandated provincial/state guidelines were less likely to have chocolate candy, sugar-sweetened beverages, and french fried potatoes (although the latter was a trend). Our data was collected 6-months prior to the deadline at which $\mathrm{BC}$ schools were expected to comply with the mandated guidelines introduced in 2005. While we do not know whether the schools have changed their environment as a result of the mandated guidelines, limiting availability of less healthful food and beverages through policy change has been associated with improved dietary intake in students [42-44]. As policies are increasingly being used to modify the school environment, it is important to assess the extent to which schools have implemented these guidelines/policies as intended to ensure decreased availability of less healthful food and beverages in schools.

The findings of this study should be interpreted in light of the limitations of the study. Firstly, associations were examined in a cross-sectional sample which precludes us from identifying factors that predict availability of food and beverages at schools. Secondly, we did not examine the extent to which the school environmental factors influenced dietary intake as this study focussed on availability as an important first step in ensuring a healthier nutritional environment. Thirdly, all measures were assessed with self-report which is known to be associated with a number of limitations. As many of the measures were developed or adapted for this study, we have limited information about the validity of these measures and whether the constructs we used were optimally operationalized. We evaluated the psychometric properties of these measures to improve the validity of our findings; however, future studies should further examine the properties of these measures. Furthermore, the availability of food and beverages was measured with an established measure [40]; however, the measure does not distinguish whether or not healthier versions were served. As schools are increasingly encouraged to provide healthier versions of less healthful food (e.g., pizza, hamburgers, and hot dogs), future studies are encouraged to incorporate this distinction in their measurement. Lastly, the food environment in public schools in Canada can vary greatly by province/state as policies or mandated guidelines are primarily set at the provincial/state level. Therefore, our findings may not be generalized to other provinces/states and countries with different structures governing the school food environment.

Students have widespread access to less healthful food and beverages at school. Therefore, there is strong support for developing school food policies/guidelines to influence the school environment. The extent to which schools can implement mandated policies/guidelines will depend to a certain extent upon factors within the school environment. This study found three environmental factors were associated with the availability of specific food/beverage items at school: having more nutritional resources, participation in provincial/state nutritional programs, and having nutritional practices that align with upcoming mandated provincial/state nutritional guidelines. As school policies/guidelines are increasingly being considered to modify the eating behavior of children at school, it is important to gain a better understanding of the factors associated with 
availability of certain food/beverage items at school to better understand factors that may facilitate attempts to change the school food environment.

\section{Competing interests}

None of the authors have any competing interests.

\section{Author's contributions}

LCM contributed to the design, data collection, data analyses, data interpretation, the drafting of the paper, and main writing to the paper. JEdN contributed to the data analyses, data interpretation, and drafting sections of the paper. All authors have read and approved the final manuscript.

\section{Acknowledgements}

This work was conducted with establishment funds from the Michael Smith Foundation for Health Research (MSFHR). Dr. Louise C. Mâsse received salary support from the MSFHR (senior scholarship), the Child and Family Research Institute located at the Children's and Women's Health Centre of British Columbia, and the Sunny Hill foundation. Dr. de Niet received post-doctoral salary support from the Child and Family Research Institute located at the Children's and Women's Health Centre of British Columbia and the Heart and Stroke Foundation. The authors would like to acknowledge Maria Valente and Louis Wong for coordinating the data collection and data entry.

Received: 4 August 2012 Accepted: 6 February 2013

Published: 19 February 2013

\section{References}

1. Belanger-Ducharme F, Tremblay A: Prevalence of obesity in Canada. Obes Rev 2005, 6(3):183-6.

2. Brownell KD, Schwartz MB, Puhl RM, Henderson KE, Harris JL: The need for bold action to prevent adolescent obesity. J Adolesc Health 2009, 45(3 Suppl):S8-17.

3. Rideout K, Levy-Milne R, Martin C, Ostry AS: Food sales outlets, food availability, and the extent of nutrition policy implementation in schools in British Columbia. Can J Public Health 2007, 98(4):246-50

4. Wechsler H, Brener ND, Kuester S, Miller C: Food service and foods and beverages available at school: results from the School Health Policies and Programs Study 2000. J Sch Health 2001, 71(7):313-24.

5. O'Toole TP, Anderson S, Miller C, Guthrie J: Nutrition services and foods and beverages available at school: results from the School Health Policies and Programs Study 2006. J Sch Health 2007, 77(8):500-21.

6. Institute of Medicine (IOM): Nutrition standards for foods in schools: leading the way toward healthier youth; 2007 [cited 2009 Apr 19]; Available from: URL: [http://books.nap.edu/openbook.php?isbn=0309103835].

7. Cullen KW, Baranowski T, Owens E, Marsh T, Rittenberry L, de MC: Availability, accessibility, and preferences for fruit, $100 \%$ fruit juice, and vegetables influence children's dietary behavior. Health Educ Behav 2003, 30(5):615-26.

8. Templeton SB, Marlette MA, Panemangalore M: Competitive foods increase the intake of energy and decrease the intake of certain nutrients by adolescents consuming school lunch. J Am Diet Assoc 2005, 105(2):215-20.

9. Harnack L, Snyder P, Story M, Holliday R, Lytle L, Neumark-Sztainer D: Availability of a la carte food items in junior and senior high schools: a needs assessment. J Am Diet Assoc 2000, 100(6):701-3.

10. Kubik MY, Lytle LA, Hannan PJ, Perry CL, Story M: The association of the school food environment with dietary behaviors of young adolescents. Am J Public Health 2003, 93(7):1168-73.

11. Cullen KW, Zakeri I: Fruits, vegetables, milk, and sweetened beverages consumption and access to a la carte/snack bar meals at school. Am J Public Health 2004, 94(3):463-7.

12. Institute of Medicine (IOM): Accelerating Progress in Obesity Prevention: Solving the Weight of the Nation. Washington, DC: The National Academies Press; 2012.

13. Cullen KW, Hartstein J, Reynolds KD, Vu M, Resnicow K, Greene N, et al: Improving the school food environment: results from a pilot study in middle schools. J Am Diet Assoc 2007, 107(3):484-9.

14. Terry-McElrath YM, O'Malley PM, Delva J, Johnston LD: The school food environment and student body mass index and food consumption: 2004 to 2007 national data. J Adolesc Health 2009, 45(3 Suppl):S45-S56.
15. Mâsse LC, Frosh MM, Chriqui JF, Yaroch AL, Agurs-Collins T, Blanck HM, et al: Development of a School Nutrition-Environment State Policy Classification System (SNESPCS). Am J Prev Med 2007, 33(4 Suppl):S277-S291.

16. Agron P, Berends V, Ellis K, Gonzalez M: School wellness policies: perceptions, barriers, and needs among school leaders and wellness advocates. J Sch Health 2010, 80(11):527-35.

17. Anderson PM, Butcher KF: Reading, writing, and refreshments: Are school finances contributing to children's obesity. J Hum Resour 2006, 41(3):467-94.

18. Johnson DB, Bruemmer B, Lund AE, Evens CC, Mar CM: Impact of school district sugar-sweetened beverage policies on student beverage exposure and consumption in middle schools. J Adolesc Health 2009, 45(3 Suppl):S30-S37.

19. French SA, Story M, Jeffery RW, Snyder P, Eisenberg M, Sidebottom A, et al: Pricing strategy to promote fruit and vegetable purchase in high school cafeterias. J Am Diet Assoc 1997, 97(9):1008-10.

20. French SA, Story M, Fulkerson JA, Hannan P: An environmental intervention to promote lower-fat food choices in secondary schools: outcomes of the TACOS Study. Am J Public Health 2004, 94(9):1507-12.

21. Hastings G, Stead M, McDermott L, Forsyth A, Mackintosh A, Rayner M, et al: Review of Research on the Effects of Food Promotion to Children; 2003. September 22 [cited 2009 Apr 15];Available from: URL: [http://www.food. gov.uk/multimedia/pdfs/foodpromotiontochildren1.pdf].

22. Institute of Medicine (IOM): Food marketing to children and youth. Committee on Food Marketing and the Diets of Children and Youth. Washington DC: National Academies Press; 2006.

23. Kubik MY, Lytle LA, Story M: Schoolwide food practices are associated with body mass index in middle school students. Arch Pediatr Adolesc Med 2005, 159(12):1111-4.

24. Long MW, Henderson KE, Schwartz MB: Evaluating the impact of a Connecticut program to reduce availability of unhealthy competitive food in schools. J Sch Health 2010, 80(10):478-86.

25. Snelling AM, Kennard T: The impact of nutrition standards on competitive food offerings and purchasing behaviors of high school students. J Sch Health 2009, 79(11):541-6.

26. Sanchez-Vaznaugh EV, Sanchez BN, Baek J, Crawford PB: 'Competitive' food and beverage policies: are they influencing childhood overweight trends? Health Aff (Millwood) 2010, 29(3):436-46.

27. Cradock AL, McHugh A, Mont-Ferguson H, Grant L, Barrett JL, Wang YC, et al: Effect of school district policy change on consumption of sugarsweetened beverages among high school students, Boston, Massachusetts, 2004-2006. Prev Chronic Dis 2011, 8(4):A74.

28. Perry $C L$, Sellers DE, Johnson C, Pedersen S, Bachman KJ, Parcel GS, et al: The Child and Adolescent Trial for Cardiovascular Health (CATCH): intervention, implementation, and feasibility for elementary schools in the United States. Health Educ Behav 1997, 24(6):716-35.

29. Franks A, Kelder SH, Dino GA, Horn KA, Gortmaker SL, Wiecha JL, et al: School-based programs: lessons learned from CATCH, Planet Health, and Not-On-Tobacco. Prev Chronic Dis 2007, 4(2):A33.

30. Parcel GS, Perry CL, Kelder SH, Elder JP, Mitchell PD, Lytle LA, et al: School climate and the institutionalization of the $\mathrm{CATCH}$ program. Health Educ Behav 2003, 30(4):489-502.

31. Wechsler H, Devereaux RS, Davis M, Collins J: Using the school environment to promote physical activity and healthy eating. Prev Med 2000, 31:S121-S137.

32. McKenna ML: Policy options to support healthy eating in schools. Can J Public Health 2010, 101(Suppl 2):S14-S17.

33. Health Canada: Canada's Food Guide - Main Page; [cited 2009 Apr 21]; Available from: URL: [http://www.hc-sc.gc.ca/fn-an/food-guide-aliment index-eng.php].

34. Stillman F, Hartman A, Graubard B, Gilpin E, Chavis D, Garcia J, et al: The American Stop Smoking Intervention Study. Conceptual framework and evaluation design. Eval Rev 1999, 23(3):259-80.

35. Hoy WK, Tarter CJ, Kottkamp RB: The organizational climate description questionnaire for elementary schools. Open Schools/Healthy Schools: Measuring Organizational Climate. Newbury Park: Sage Publications; 1991:25-45.

36. Hoy WK, Hannum JW: Middle school climate: An empirical assessment of organizational health and student achievement. EduC Adm Q 1997, 33(3):290-311

37. Hoy WK: Measuring the Health of the School Climate: A Conceptual Framework. NASSP Bull 1992, 76:74. 
38. Hoy WK: The Development of the Organizational Climate Index for High Schools: Its Measure and Relationship to Faculty Trust. High Sch J 2002, 86(2):38-50

39. Hoy WK, Tarter CJ, Kottkamp RB: The organizational health inventory for elementary schools. Open Schools/Healthy Schools: Measuring Organizational Climate. Newbury Park: Sage Publications; 1991:85-106.

40. Centers for Chronic Disease and Prevention: Healthy Youth: SHPPS 2006 Data Files and Documentation; 2006 [cited 2007 Jun 1]; Available from: URL: [http://www.cdc.gov/healthyyouth/shpps/2006/factsheets/pdf/ FS_Overview_SHPPS2006.pdf].

41. Sterne JA, White IR, Carlin JB, Spratt M, Royston P, Kenward MG, et al: Multiple imputation for missing data in epidemiological and clinical research: potential and pitfalls. BMJ 2009, 338:b2393.

42. Mullally ML, Taylor JP, Kuhle S, Bryanton J, Hernandez KJ, MacLellan DL, et al: A province-wide school nutrition policy and food consumption in elementary school children in Prince Edward Island. Can J Public Health 2010, 101(1):40-3.

43. Cullen KW, Watson K, Zakeri I: Improvements in middle school student dietary intake after implementation of the Texas Public School Nutrition Policy. Am J Public Health 2008, 98(1):111-7.

44. Veugelers PJ, Fitzgerald AL: Effectiveness of school programs in preventing childhood obesity: a multilevel comparison. Am J Public Health 2005, 95(3):432-5.

doi:10.1186/1479-5868-10-26

Cite this article as: Mâsse and de Niet: School nutritional capacity, resources and practices are associated with availability of food/ beverage items in schools. International Journal of Behavioral Nutrition and Physical Activity 2013 10:26

\section{Submit your next manuscript to BioMed Central and take full advantage of:}

- Convenient online submission

- Thorough peer review

- No space constraints or color figure charges

- Immediate publication on acceptance

- Inclusion in PubMed, CAS, Scopus and Google Scholar

- Research which is freely available for redistribution 